\section{Polyhedral Vanadium Oxide Cages: Infrared Spectra of Cluster Anions and Size-Induced d Electron Localization**}

\author{
Knut R. Asmis, * Gabriele Santambrogio, \\ Mathias Brümmer, and Joachim Sauer*
}

The size-dependent properties of transition metal oxide clusters have been intensely studied not only because of interest in this peculiar state of matter, but also because of their relevance as building blocks for nanostructured materials. Vanadium oxides, in particular, are important in supported catalysts, ${ }^{[1]}$ as cathode materials in lithium batteries, ${ }^{[2]}$ in bolometric detectors, ${ }^{[3]}$ and as ferromagnetic nanotubes. ${ }^{[4]}$ While the structural characterization of vanadium oxide clusters deposited on surfaces ${ }^{[5]}$ has reached atomic resolution, it remains a major experimental challenge in the gas

\footnotetext{
[*] Dr. K. R. Asmis

Fritz-Haber-Institut der Max-Planck-Gesellschaft

Faradayweg 4-6, 14195 Berlin (Germany)

Fax: (+49) 308-413-5603

E-mail: asmis@fhi-berlin.mpg.de

Prof. Dr. J. Sauer

Institut für Chemie, Humboldt-Universität Berlin

Unter den Linden 6, 10099 Berlin (Germany)

Fax: (+49) 302-093-7136

E-mail: js@chemie.hu-berlin.de

Dipl.-Phys. G. Santambrogio, Dipl.-Ing. M. Brümmer

Institut für Experimentalphysik, Freie Universität Berlin

Arnimallee 14, 14195 Berlin (Germany)

[***] This work was supported by the German Research Foundation (DFG) as part of the Collaborative Research Center 546. We gratefully acknowledge the support of the "Stichting voor Fundamenteel Onderzoek der Materie (FOM)" in providing the required beam time on FELIX and highly appreciate the skilful assistance of the FELIX staff. We thank L. Wöste and G. Meijer for their continuous support and A. Fielicke for helpful discussions. Supporting information for this article is available on the WWW under http://www.angewandte.org or from the author.
}

phase. ${ }^{[6]}$ Infrared photodissociation ${ }^{[7]}$ paired with quantum chemistry is currently the most generally applicable approach for cluster ions even though it requires intense and tunable infrared radiation sources. Below $2000 \mathrm{~cm}^{-1}$, in the fingerprint region of metal oxide clusters, only free-electron lasers meet these demands. ${ }^{[8]}$

Herein we report the first experimental infrared spectra of transition metal oxide cluster anions in the gas phase. We combine infrared multiple photon dissociation (IRMPD) spectroscopy with density functional theory (DFT) to characterize the geometric and electronic structures of a representative series of vanadium oxide cluster anions, $\left(\mathrm{V}_{2} \mathrm{O}_{5}\right)_{n}$ ( $n=2,3$, or 4) $\cdot{ }^{[9]}$ Compelling evidence is produced that these anions have the polyhedral cage structures that have been predicted before, but have eluded spectroscopic detection until now. ${ }^{[10,11]}$ Evidence is also found for a size-induced localization of the extra electron in this series of anions.

The IRMPD spectra of mass-selected $\mathrm{V}_{4} \mathrm{O}_{10}{ }^{-}, \mathrm{V}_{6} \mathrm{O}_{15}{ }^{-}$, and $\mathrm{V}_{8} \mathrm{O}_{20}{ }^{-}$are shown on the left in Figure 1. They were measured by irradiating vibrationally cold, mass-selected parent ions with intense, tunable IR radiation from the free-electron laser FELIX $^{[12]}$ and monitoring the mass-selected fragment ion yield as a function of laser wavelength. Only when the radiation is resonant with a fundamental vibrational transition can the cluster ions absorb photons, thereby initiating a sequential multiphoton absorption process ${ }^{[13]}$ which leads to heating of the cluster ion and eventually to photodissociation. The simplicity of the $\mathrm{V}_{4} \mathrm{O}_{10}{ }^{-}$spectrum is striking and immediately suggests a structure of higher symmetry with degenerate transitions. The dominant feature is a single, rather narrow intense band at $990 \mathrm{~cm}^{-1}$. Based on our previous measurements on vanadium oxide cluster cations it is assigned to a vanadyl stretching mode. ${ }^{[14]}$ The weaker signal below $750 \mathrm{~cm}^{-1}$ is attributed to a $\mathrm{V}-\mathrm{O}-\mathrm{V}$ stretch. The IRMPD spectrum of $\mathrm{V}_{8} \mathrm{O}_{20}{ }^{-}$is markedly different. While the vanadyl band stays nearly unchanged, a new band, much broader and roughly four times stronger than the vanadyl band, is observed centered at $870 \mathrm{~cm}^{-1}$. The appearance of the $\mathrm{V}_{6} \mathrm{O}_{15}{ }^{-}$spectrum is intermediate between the spectra described above. An intense vanadyl band, somewhat broader and red-shifted, is followed by a four times less intense band at $830 \mathrm{~cm}^{-1}$. No signal is observed below $700 \mathrm{~cm}^{-1}$ for the two larger clusters.

To understand these vibrational spectra we performed DFT calculations (B3LYP functional ${ }^{[15,16]}$ ) of cluster geometries and vibrational spectra (see Figure 1). All three anions are open-shell systems with a single unpaired electron. For $\mathrm{V}_{4} \mathrm{O}_{10}{ }^{-}$we find a tetragonal $D_{2 d}$ structure (1) which is minimally Jahn-Teller distorted from the $T_{d}$ structure. Each vanadium atom is fourfold coordinated, forming one short $\mathrm{V}=$ $\mathrm{O}$ bond $(159 \mathrm{pm})$ and three $\mathrm{V}-\mathrm{O}$ bonds $(181 \mathrm{pm})$. The four symmetry-equivalent vanadyl bond stretches combine to give three IR-active $b_{2}$ and $e$ modes, which are quasi-degenerate and explain the single intense vanadyl band in the IRMPD spectrum. The six symmetric $\mathrm{V}-\mathrm{O}-\mathrm{V}$ bond stretches also give rise to three IR-active $e$ and $b_{2}$ modes $\left(629\right.$ and $609 \mathrm{~cm}^{-1}$, respectively), and they have a cumulative oscillator strength that is about $1 / 3$ that of the vanadyl bands, in good agreement with experiment. The modes resulting from the six antisym- 

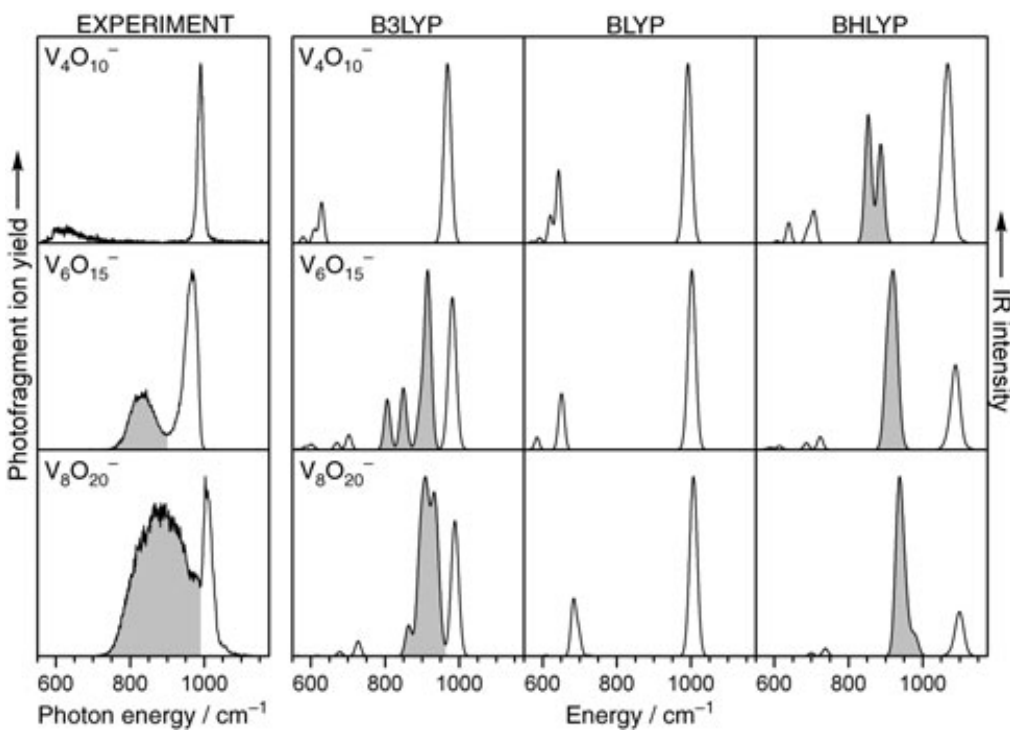

Figure 1. Experimental and simulated vibrational spectra of vanadium oxide cluster anions in the region of the $\mathrm{V}-\mathrm{O}$ and $\mathrm{V}=\mathrm{O}$ bond stretch modes. IRMPD spectra (left) of $\mathrm{V}_{4} \mathrm{O}_{10}{ }^{-}, \mathrm{V}_{6} \mathrm{O}_{15}{ }^{-}$, and $\mathrm{V}_{8} \mathrm{O}_{20}{ }^{-}$were measured from 550 to $1175 \mathrm{~cm}^{-1}$ by monitoring the dominant fragmentation channel, which leads to the formation of $\mathrm{V}_{3} \mathrm{O}_{8}{ }^{-}, \mathrm{V}_{4} \mathrm{O}_{10}{ }^{-}$, and $\mathrm{V}_{4} \mathrm{O}_{10}{ }^{-}$, respectively. Simulated spectra (right) were obtained from scaled harmonic frequencies and oscillator strengths employing the B3LYP, BLYP, and BHLYP functionals. The calculated stick spectra were convoluted for better comparison with the experiment. Gray shaded peaks indicate localization of the unpaired d electron (see text).

metric $\mathrm{V}-\mathrm{O}-\mathrm{V}$ bond stretches are below $600 \mathrm{~cm}^{-1}$ and have vanishingly low intensities.

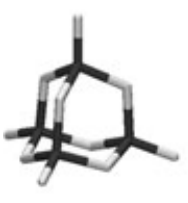

1

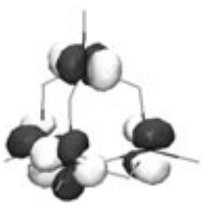

$\operatorname{SONO}(1)$

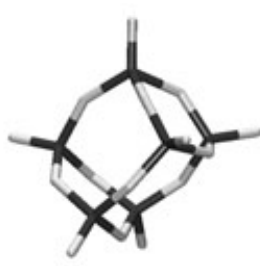

2

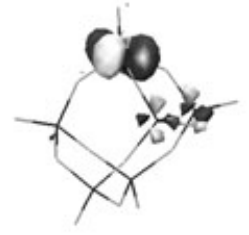

SONO(2)

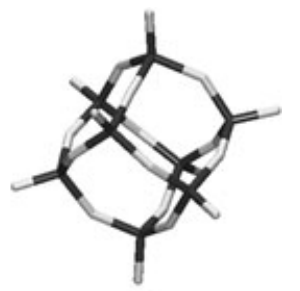

3

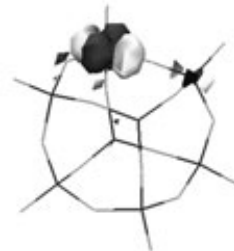

$\operatorname{SONO}(3)$
In $\mathrm{V}_{4} \mathrm{O}_{10}{ }^{-}$the unpaired electron is completely delocalized over d-states of all four vanadium sites, as illustrated by its singly-occupied natural orbital $\operatorname{SONO}(\mathbf{1})$. In contrast, in the larger anions the unpaired electron is localized at a single vanadium site, which lowers the symmetry of their structures to $C_{s}$. For $\mathrm{V}_{6} \mathrm{O}_{15}{ }^{-}$and $\mathrm{V}_{8} \mathrm{O}_{20}{ }^{-}$we find the distorted trigonal prism and cube structures 2 and $\mathbf{3}$. Their singly occupied natural orbitals, $\operatorname{SONO}(2)$ and $\operatorname{SONO}(3)$, reflect the localization of the unpaired electron. Compared to $\mathrm{V}_{4} \mathrm{O}_{10}{ }^{-}$, the average $\mathrm{V}-\mathrm{O}(-\mathrm{V})$ bond distances in $\mathrm{V}_{8} \mathrm{O}_{20}{ }^{-}$are longer at the electron localization site $(189 \mathrm{pm})$, but shorter at the other sites (177-178 pm), while the $\mathrm{V}=\mathrm{O}$ bond distances are similar and not affected by the localization. Unlike the closed-shell neutral parent compounds, the $D_{3 h}$ structure (trigonal prism) of $\mathrm{V}_{6} \mathrm{O}_{15}{ }^{-}$and the $D_{2 d}$ structure (cube) of $\mathrm{V}_{8} \mathrm{O}_{20}{ }^{-}$are higher-order saddle points that are 45 and $21 \mathrm{~kJ} \mathrm{~mol}^{-1}$, respectively, above the ground state. For both $\mathrm{V}_{6} \mathrm{O}_{15}{ }^{-}$and $\mathrm{V}_{8} \mathrm{O}_{20}{ }^{-}$first-order saddle points with $C_{2 v}$ symmetry are found 9.8 and $8.7 \mathrm{~kJ} \mathrm{~mol}^{-1}$, respectively, above the ground state. They represent transition structures for the interconversion of two equivalent $C_{\mathrm{s}}$-minimum structures and have the additional electron delocalized over two sites.

The effects of symmetry breaking are directly observed in the vibrational spectra of these species (indicated by the gray-shaded area in Figure 1). Upon localization of the unpaired electron intense $\mathrm{V}-\mathrm{O}-\mathrm{V}$ stretch transitions appear at around $100-200 \mathrm{~cm}^{-1}$ below the strong vanadyl band, which replace the weak $\mathrm{V}-\mathrm{O}-\mathrm{V}$ feature more than $350 \mathrm{~cm}^{-1}$ below the vanadyl band in the spectrum of the delocalized case $\left(\mathrm{V}_{4} \mathrm{O}_{10}{ }^{-}\right)$. The calculated ratio of the cumulative oscillator strengths of the $\mathrm{V}-\mathrm{O}-\mathrm{V}$ modes and the $\mathrm{V}=\mathrm{O}$ modes is 3.3 for $\mathrm{V}_{8} \mathrm{O}_{20}{ }^{-}$and 0.3 for $\mathrm{V}_{4} \mathrm{O}_{10}{ }^{-}$; these values compare well to the experimental values of 4.4 and 0.4 respectively. The vanadyl modes are not affected by the electron localization and therefore their position and width remain nearly unchanged. Comparison with the experimental infrared spectra confirms the general predictions of the B3LYP model, in particular the pronounced, qualitative changes upon electron localization when the size of the cluster is increased. ${ }^{[17]}$

Figure 1 shows not only the B3LYP results discussed so far, but also the results of DFT calculations with the $\mathrm{BLYP}^{[16,18]}$ and BHLYP ${ }^{[16,19]}$ functionals. The increasing admixture of Fock exchange $(0,20$, and $50 \%$ in BLYP, B3LYP, and BHLYP, respectively) leads to an increasing tendency for symmetry breaking. ${ }^{[2-22]}$ BHLYP (right column in Figure 1) yields localization of the unpaired electron for all three cage-type anions, and also for $\mathrm{V}_{4} \mathrm{O}_{10}{ }^{-}$. Consequently, the calculated BHLYP spectrum of $\mathrm{V}_{4} \mathrm{O}_{10}{ }^{-}$shows additional bands between 800 and $900 \mathrm{~cm}^{-1}$ that are absent from the experimental spectrum. In contrast, BLYP predicts delocalization of the unpaired electron for all three cage-type anions studied and $C_{2 v}$ and $D_{2 \mathrm{~d}}$ structures become the ground states of $\mathrm{V}_{6} \mathrm{O}_{15}{ }^{-}$and $\mathrm{V}_{8} \mathrm{O}_{20}{ }^{-}$, respectively. All three BLYP spectra show no bands between 750 and $950 \mathrm{~cm}^{-1}$, which is in clear contrast with the experimental spectra of $\mathrm{V}_{6} \mathrm{O}_{15}{ }^{-}$and $\mathrm{V}_{8} \mathrm{O}_{20}{ }^{-}$. In summary, Figure 1 shows that only B3LYP reproduces correctly the transition from symmetric (delocalized) to broken-symmetry (localized) structures when passing from $\mathrm{V}_{4} \mathrm{O}_{10}{ }^{-}$to $\mathrm{V}_{6} \mathrm{O}_{15}{ }^{-}$in this series of $\left(\mathrm{V}_{2} \mathrm{O}_{5}\right)_{n}{ }^{-}$cluster anions.

Figure 2 compares the gas-phase IRMPD spectrum of $\mathrm{V}_{8} \mathrm{O}_{20}{ }^{-}$with the electron energy loss spectrum of a $\mathrm{V}_{2} \mathrm{O}_{5}$ 

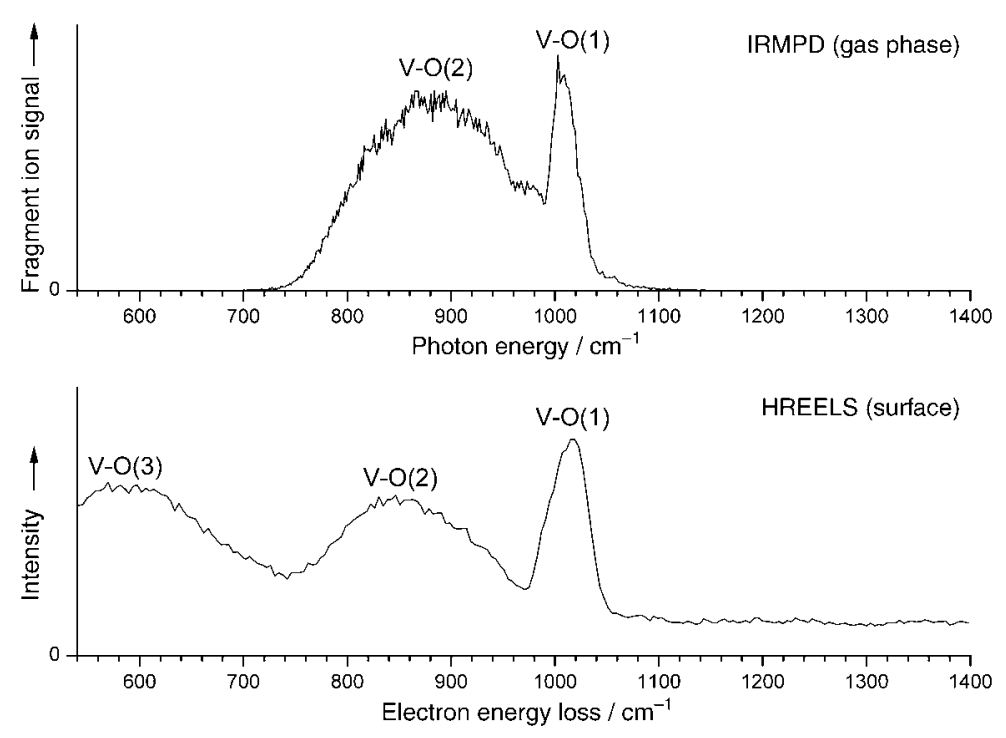

Figure 2. Vibrational spectra of different forms of vanadium oxide: The IRMPD spectrum of the gas-phase cluster anion $\mathrm{V}_{8} \mathrm{O}_{20}{ }^{-}$(top) and the spectrum of a freshly cleaved 001 surface of $\mathrm{V}_{2} \mathrm{O}_{5}$ (bottom), measured by high resolution electron energy loss spectroscopy (see text).

surface, ${ }^{[23]}$ which also probes vibrational states. The spectra are surprisingly similar in the region above $740 \mathrm{~cm}^{-1}$, with both displaying two bands of similar width and relative intensity. Their assignment is identical, that is, to vibrational modes of singly and doubly coordinated oxygen atoms. The third broad band of the surface spectrum is not observed in the gas phase. This can easily be rationalized because this band is assigned ${ }^{[11,24]}$ to triply coordinated oxygen sites, which do not exist in the $\mathrm{V}_{8} \mathrm{O}_{20}{ }^{-}$cluster anion. Hence, the vibrational spectra reflect clearly the common $(\mathrm{V}=\mathrm{O}$ and $\mathrm{V}-\mathrm{O}-\mathrm{V}$ bonds) and the discriminating (triply coordinated $\mathrm{O}$ ) structural features of gas-phase clusters and solid surfaces. ${ }^{[25,26]}$

In this communication the polyhedral cage structures of $\left(\mathrm{V}_{2} \mathrm{O}_{5}\right)_{n}{ }^{-}$clusters $(n=2,3,4)$ have been identified spectroscopically for the first time by IRMPD spectroscopy. We have also found evidence for size-dependent charge localization in these clusters. Symmetry-breaking localization is observed in many other chemical systems for the reverse processcreation of an electron hole. ${ }^{[21]}$ For example, the electron hole created in quartz when doped with $\mathrm{Al}$ is not delocalized over all four oxygen sites of the $\mathrm{AlO}_{4}$ defect site, but localized at one oxygen only. ${ }^{[2]}$ The proper description of electron (hole) localization phenomena by DFT depends on the functional used. In the present case we use the measured IRMPD spectra as the criteria for selecting the proper functional and find that only B3LYP has the right admixture of Fock exchange to reproduce the size-dependent change from delocalized to localized d electron states in vanadium oxide cages correctly. Even though the largest cluster anion studied here, $\mathrm{V}_{8} \mathrm{O}_{20}{ }^{-}$, is still rather small, it reveals some striking similarities with the properties of a vanadium oxide single-crystal surface, making it an interesting gas-phase model for surface adsorption and reactivity studies.

\section{Experimental Section}

The present experiments were carried out on a previously described tandem mass spectrometer-ion trap system. ${ }^{[27]}$ Vanadium oxide clusters were prepared by pulsed laser vaporization of a vanadium rod in the presence of $\mathrm{O}_{2}$ seeded in He. The beam of negative ions was collimated and mass-selected by a quadrupole mass filter. Massselected cluster ions were accumulated and cooled to $15 \mathrm{~K}$ in a linear radio-frequency ion trap. IR photodissociation spectra were obtained by photoexcitation of the trapped cold ions with pulsed radiation from the FELIX, ${ }^{[12]}$ and subsequent monitoring of the mass-selective ion yield. A FELIX bandwidth (RMS) of less than $0.3 \%$ of the central wavelength and pulse energies up to $60 \mathrm{~mJ}$ per macropulse were used.

Unrestricted Kohn--Sham calculations were performed with TURBOMOLE. ${ }^{[28]}$ Triple-zeta valence plus polarization basis sets (TZVP) were applied. ${ }^{[29]}$ Harmonic vibrational frequencies were obtained from second analytic derivatives ${ }^{[30]}$ and were scaled using standard procedures (see Supporting Information).

Received: December 10, 2004

Published online: April 13, 2005

Keywords: cluster compounds · density functional calculations - electronic structure - IR spectroscopy - vanadium

[1] B. M. Weckhuysen, D. E. Keller, Catal. Today 2003, 78, 25-46.

[2] M. S. Whittingham, Chem. Rev. 2004, 104, 4271-4301.

[3] L. A. L. de Almeida, G. S. Deep, A. M. N. Lima, I. A. Khrebtov, V. G. Malyarov, H. Neff, Appl. Phys. Lett. 2004, 85, $3605-3607$.

[4] L. Krusin-Elbaum, D. M. Newns, H. Zeng, V. Derycke, J. Z. Sun, R. Sandstrom, Nature 2004, 431, 672-676.

[5] a) J. Schoiswohl, G. Kresse, S. Surnev, M. Sock, M. G. Ramsey, F. P. Netzer, Phys. Rev. Lett. 2004, 92, 206103; b) N. Magg, B. Immaraporn, J. B. Giorgi, T. Schroeder, M. Bäumer, J. Döbler, Z. L. Wu, E. Kondratenko, M. Cherian, M. Baerns, P. C. Stair, J. Sauer, H.-J. Freund, J. Catal. 2004, 126, 88-100.

[6] a) A. Dinca, T. P. Davis, K. J. Fisher, D. R. Smith, G. D. Willett, Int. J. Mass Spectrom. 1999, 182/183, 73-84; b) R. C. Bell, K. A. Zemski, D. R. Justes, A. W. Castleman, Jr., J. Chem. Phys. 2001, 114, 798-811; c) H. J. Zhai, L.-S. Wang, J. Chem. Phys. 2002, 117, $7882-7888$; d) A. Pramann, K. Koyasu, A. Nakajima, K. Kaya, J. Chem. Phys. 2002, 116, 6521-6528.

[7] M. A. Duncan, Int. J. Mass Spectrom. 2000, 200, 545-569.

[8] G. von Helden, D. van Heijnsbergen, G. Meijer, J. Phys. Chem. A 2003, 107, 1671-1688.

[9] A systematic study of vanadium oxide cluster anions containing two to eight vanadium atoms will be reported shortly.

[10] S. F. Vyboishchikov, J. Sauer, J. Phys. Chem. A 2000, 104, $10913-$ 10922.

[11] S. F. Vyboishchikov, J. Sauer, J. Phys. Chem. A 2001, 105, $8588-$ 8598.

[12] D. Oepts, A. F. G. van der Meer, P. W. van Amersfoort, Infrared Phys. Technol. 1995, 36, 297-308.

[13] J. Oomens, G. Meijer, G. von Helden, J. Phys. Chem. A 2001, 105, $8302-8309$.

[14] K. R. Asmis, G. Meijer, M. Brümmer, C. Kaposta, G. Santambrogio, L. Wöste, J. Sauer, J. Chem. Phys. 2004, 120, 6461-6470.

[15] A. D. Becke, J. Chem. Phys. 1993, 98, 5648-5652.

[16] C. Lee, W. Yang, R. G. Parr, Phys. Rev. B 1988, 37, 785-789.

[17] Some discrepancies between experimental and simulated spectra remain and are attributed to the approximate nature of the calculations, which neglect the multiphotonic nature of the absorption process and assume that the potentials are single-well and harmonic. 
[18] A. D. Becke, Phys. Rev. A 1988, 38, 3098-3100.

[19] A. D. Becke, J. Chem. Phys. 1993, 98, 1372-1377.

[20] C. D. Sherrill, M. S. Lee, M. Head-Gordon, Chem. Phys. Lett. 1999, 302, 425-430.

[21] M. Sodupe, J. Bertran, L. Rodriguez-Santiago, E. J. Baerends, J. Phys. Chem. A 1999, 103, 166-170.

[22] G. Pacchioni, F. Frigoli, D. Ricci, J. A. Weil, Phys. Rev. B 2001, 63, 054102; X. Solans-Monfort, V. Branchadell, M. Sodupe, M. Sierka, J. Sauer, J. Chem. Phys. 2004, 121, 6034-6041.

[23] B. Tepper, B. Richter, A. C. Dupuis, H. Kuhlenbeck, C. Hucho, P. Schilbe, M. A. bin Yarmo, H.-J. Freund, Surf. Sci. 2002, 496, $64-72$.

[24] V. Brázdová, M. V. Ganduglia-Pirovano, J. Sauer, Phys. Rev. B 2004, 69, 165420.

[25] In solid compounds, mixed-valence polyvanadate species, such as $\mathrm{V}_{15} \mathrm{O}_{36}{ }^{5-}$, are found which also have a cage structure with terminal $\mathrm{V}=\mathrm{O}$ groups, but contain triply coordinated $\mathrm{O}$ in addition to $\mathrm{V}-\mathrm{O}-\mathrm{V}$ bonds. See ref. [26].

[26] A. Müller, E. Krickemeyer, M. Penk, H.-J. Walberg, H. Bögge, Angew. Chem. 1987, 99, 1060-1061; Angew. Chem. Int. Ed. Engl. 1987, 26, 1045-1046.

[27] K. R. Asmis, M. Brümmer, C. Kaposta, G. Santambrogio, G. von Helden, G. Meijer, K. Rademann, L. Wöste, Phys. Chem. Chem. Phys. 2002, 4, 1101-1104.

[28] a) R. Ahlrichs, M. Bär, M. Häser, H. Horn, C. Kölmel, Chem. Phys. Lett. 1989, 162, 165-169; b) O. Treutler, R. Ahlrichs, J. Chem. Phys. 1995, 102, 346-354; c) K. Eichkorn, O. Treutler, H. Öhm, M. Häser, R. Ahlrichs, Chem. Phys. Lett. 1995, 242, $652-$ 660.

[29] A. Schäfer, C. Huber, R. Ahlrichs, J. Chem. Phys. 1994, 100, $5829-5835$.

[30] P. Deglmann, F. Furche, R. Ahlrichs, Chem. Phys. Lett. 2002, 362, $511-518$. 